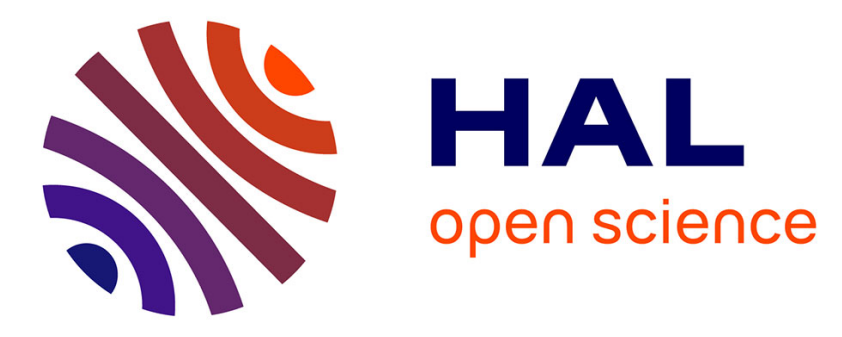

\title{
Chiral Nanographene Propeller Embedding Six Enantiomerically Stable [5]Helicene Units
}

Veronika Berezhnaia, Myriam Roy, Nicolas Vanthuyne, Marc Villa, Jean

Naubron, Jean Rodriguez, Yoann Coquerel, Marc Gingras

\section{To cite this version:}

Veronika Berezhnaia, Myriam Roy, Nicolas Vanthuyne, Marc Villa, Jean Naubron, et al.. Chiral Nanographene Propeller Embedding Six Enantiomerically Stable [5]Helicene Units. Journal of the American Chemical Society, 2017, 139 (51), pp.18508-18511. 10.1021/jacs.7b07622 . hal-01683221

\section{HAL Id: hal-01683221 \\ https://hal.science/hal-01683221}

Submitted on 16 Apr 2018

HAL is a multi-disciplinary open access archive for the deposit and dissemination of scientific research documents, whether they are published or not. The documents may come from teaching and research institutions in France or abroad, or from public or private research centers.
L'archive ouverte pluridisciplinaire HAL, est destinée au dépôt et à la diffusion de documents scientifiques de niveau recherche, publiés ou non, émanant des établissements d'enseignement et de recherche français ou étrangers, des laboratoires publics ou privés. 


\section{Chiral Nanographene Propeller Embedding Six Enantiomerically Stable [5]Helicene Units}

Veronika Berezhnaia, ${ }^{\dagger}$ Myriam Roy $^{\dagger}$ Nicolas Vanthuyne, $^{\ddagger}$ Marco Villa, ${ }^{\dagger}$ Jean-Valère Naubron, ${ }^{\S}$ Jean Rodriguez, ${ }^{\ddagger}$ Yoann Coquerel, $*,+(0)$ and Marc Gingras $*{ }^{*}+$ (1)

${ }^{\dagger}$ Aix Marseille Université, CNRS, CINAM, 13288 Marseille, France

${ }^{\ddagger}$ Aix Marseille Université, CNRS, Centrale Marseille, ISM2, 13288 Marseille, France

${ }^{\S}$ Aix Marseille Université, CNRS, Centrale Marseille, FR1739, 13288 Marseille, France

Supporting Information

ABSTRACT: A one-step synthesis of a nanographene propeller with a $D_{3}$-symmetry was obtained starting from 7,8-dibromo[5] helicene by Yamamoto nickel(0) couplings. It afforded a chiral polyaromatic hydrocarbon (PAH) embedding six enantiomerically stable [5]helicene units. This dense accumulation of helical strain resulted in a distorted geometry, but stable stereochemistry. The conformational, structural, chiroptical, and photophysical properties of the molecule are reported.

$\mathrm{C}$ urved polyaromatic hydrocarbons (PAHs) with extended $\pi$-systems are of great interest in materials science, especially in research on nanographenes, nanoribbons, and distorted graphene sheets with peculiar topology. ${ }^{1}$ Following this trend, a challenge is to design and to synthesize large, nonplanar, and molecularly defined PAHs. However, the ultimate challenge in this field is probably to exploit chirality as a parameter to finetune and to fully exalt organic materials properties, such as their physical, supramolecular (solid-state packing, homochiral/ heterochiral interactions), photophysical, conductive, chiroptical, molecular recognition, and switching properties. ${ }^{2}$

A historical approach to induce chirality in PAHs has been to generate helicity from van der Waals repulsion (strain), such as a deviation from planarity in consecutive ortho-fused benzene rings for making helicenes. ${ }^{3}$ In this context, elongated and laterally $\pi$ extended carbohelicenes are two important classes of molecules. ${ }^{4}$ When it comes to large PAHs, some curved molecules can exhibit conformational flexibility with unique dynamic behaviors, and thus cannot be easily obtained as single enantiomers under standard conditions. Up to now, a restricted number of configurationally stable, helicene-based large PAHs with stable chiroptical properties have been described, essentially because of difficulties in synthesizing such crowded molecules. Among the few successful approaches toward this end, most have relied on accumulation of helical strain from the combination of two or more helical units, ${ }^{5}$ with up to a quadruple helicene being recently reported by Itami and co-workers. ${ }^{5 \mathrm{~b}}$

In this context, we have designed the chiral propeller-shaped $D_{3}$-symmetric PAH 2 embedding a high density of [5] helicene units (three external and three internal). It could potentially be configurationally stable and resolved in enantiopure forms, toward future applications in materials science and chiroscience (Scheme 1).

Scheme 1. $[2+2+2]$ Cyclotrimerization Routes to Triphenylene 1a, Higher Order Analogues 1b, and Propeller 2 Embedding Six [5]Helicene Units

(a) Synthetic routes to triphenylenes by cyclotrimerization

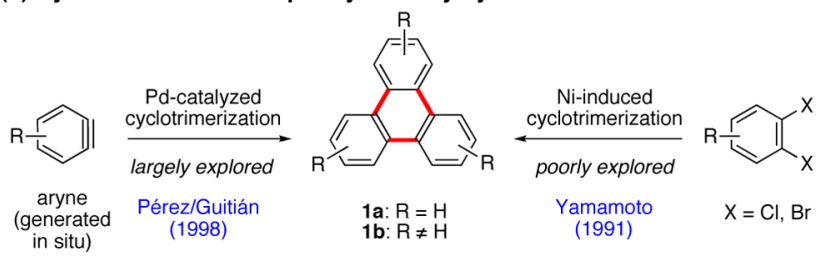

(b) Synthesis of the propeller-shaped chiral nanographene 2

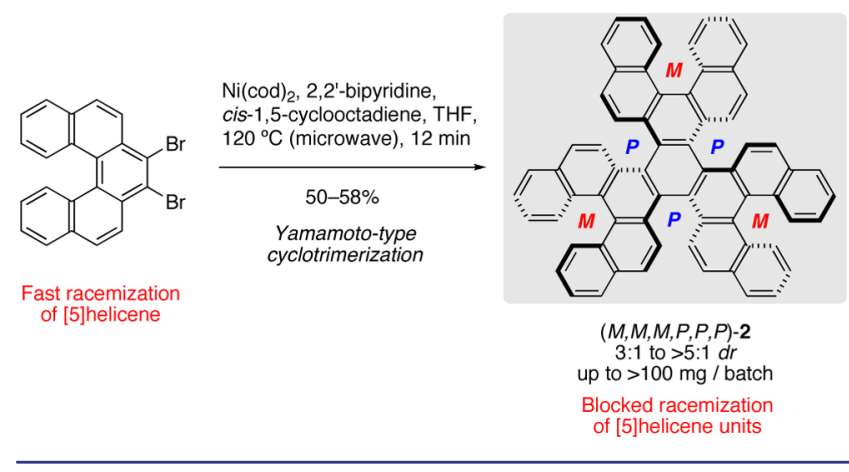

The syntheses of propeller-shaped molecules with a $D_{3}$ symmetry have largely relied on a $[2+2+2]$ cyclotrimerization of the corresponding arynes. ${ }^{6}$ For example, triphenylene $1 \mathbf{a}^{7}$ and higher order analogues $\mathbf{1 b}^{8}$ can be obtained by palladiumcatalyzed $[2+2+2]$ cyclotrimerization of arynes (Scheme 1 ). In contrast, cyclotrimerizations from Yamamoto-type nickel(0) couplings of ortho-dibromoarenes have been rarely employed in this series, never with helicenes. ${ }^{9}$ Importantly, propellers from triphenylenes of generic formula $\mathbf{1 b}$ have enough flexibility to exhibit conformational dynamics, precluding their isolation in enantiopure form. ${ }^{8,9}$ We reasoned 2 would possess higher steric interactions and would require more energy for a molecular deformation than for $\mathbf{1 b}$, due to an accumulation of helical strains

Received: July 20, 2017

Published: October 17, 2017 


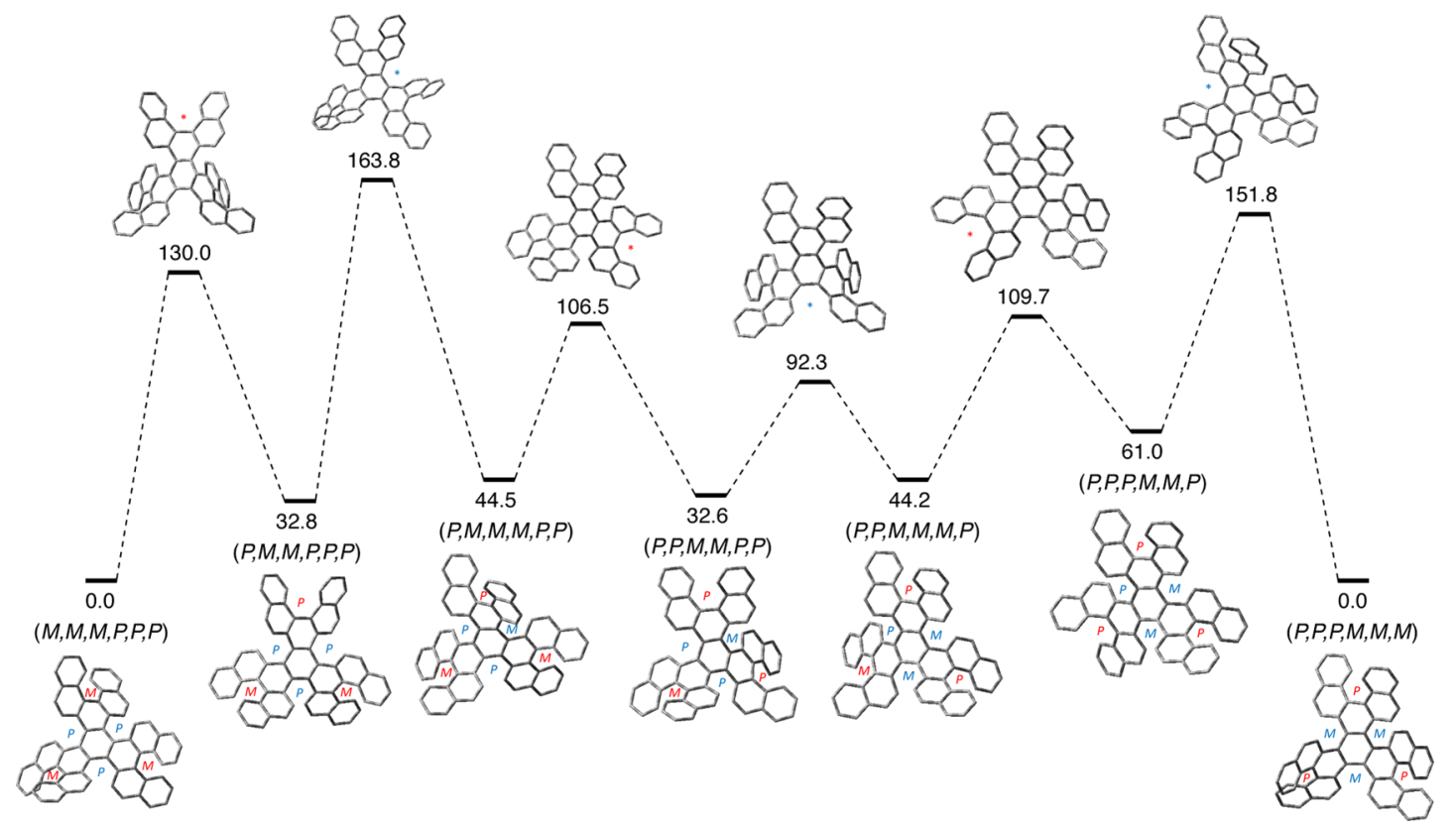

Figure 1. Conformational dynamics (in part) and plausible enantiomerization pathway of 2. DFT calculations performed at the B3LYP/6-31G(d) level of theory in the gas phase, free energies are thermally corrected and expressed in $\mathrm{kJ} \mathrm{mol}^{-1}$, see Supporting Information for details.

with six embedded helical units. Thus, 2 may form a configurationally stable propeller with six stable [5] helicene motifs.

Before starting the challenging synthesis of 2 , we conducted a brief computational study on the conformational dynamics of 2 (Figure 1). In our stereochemical nomenclature for $\mathbf{2}$, the helicity of three external [5] helicenes precedes the helicity of three internal ones in going clockwise, from the top external [5] helicene (see Scheme 1). Ten diastereomers of 2 were identified with relative energies ranging from 0 to $108.8 \mathrm{~kJ} \mathrm{~mol}^{-1}$ (see SI). As illustrated in Figure 1, the most stable diastereomer of 2 exhibits the anticipated $(M, M, M, P, P, P)$ configuration. Two pathways were computationally identified for the enantiomerization process of $(M, M, M, P, P, P)-\mathbf{2}$, and the most favorable one is presented in Figure 1. These calculations convey two important results: (i) the $(M, M, M, P, P, P)-2$ diastereomer is the thermodynamic one; (ii) the enantiomerization barrier is evaluated to $163.8 \mathrm{~kJ} \mathrm{~mol}^{-1}$, indicating a configurational stability of $(M, M, M, P, P, P)-2$ at room temperature. ${ }^{10}$ We later found the experimental barrier of enantiomerization of $(M, M, M, P, P, P)-2$ to be $147.0 \mathrm{~kJ} \mathrm{~mol}^{-1}$ at $182{ }^{\circ} \mathrm{C}$ in 1,2 -dichlorobenzene $\left(t_{1 / 2}=45\right.$ min, see SI). This value is in the range of a [6]helicene enantiomerization $\left(\sim 150 \mathrm{~kJ} \mathrm{~mol}^{-1}\right)$. Confident in our design, we turned our attention to the synthesis of 2 . Because we had a procedure for the preparation of multigram amounts of 7,8dibromo[5] helicene, ${ }^{11}$ and because of the practicality in using 1,2-dihalogenoarenes instead of complex and difficult to prepare aryne precursors, we devised a cyclotrimerization from $\mathrm{Ni}(0)$ induced Yamamoto $\mathrm{C}-\mathrm{C}$ couplings ${ }^{9}$ under modified conditions in THF at $120^{\circ} \mathrm{C}$, under microwave irradiation. ${ }^{12}$ Rewardingly, the racemic product $(M, M, M, P, P, P)-2$ was obtained as the major diastereomer together with a minor one $(3: 1$ to $>5: 1 d r)$ in a 50$58 \%$ yield on a $>100 \mathrm{mg}$ scale (Scheme $1 \mathrm{~b}$ ). The structural identification of $(M, M, M, P, P, P)-2$ was ascertained by several methods: ${ }^{1} \mathrm{H}$ and ${ }^{13} \mathrm{C}$ NMR, HRMS, and X-ray diffraction from a monocrystal. The final purity of 2 was evaluated to be $>95 \%$. As for the diastereoselectivity of the reaction, we hypothesized a thermodynamic control with an isomerization pathway, as shown in Figure 1. Indeed, a 1:1 mixture of 2 and its diastereomer of unknown configuration could be converted into diastereomerically pure 2 by microwave heating in THF at $120^{\circ} \mathrm{C}$ for $30 \mathrm{~min}$ (see details in SI).

A recrystallization of racemic 2 afforded monocrystals with both enantiomers in the same crystal lattice (Figure 2). Among

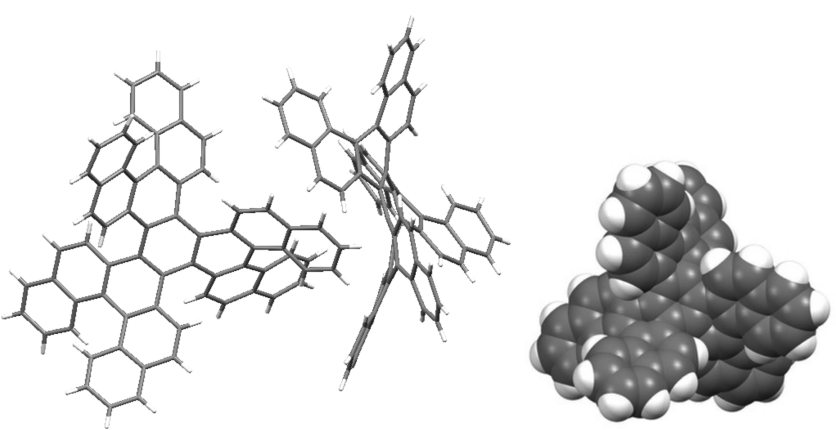

Figure 2. 3D representations of $( \pm)$-2 obtained from single-crystal Xray diffraction with two enantiomers cocrystallized in the same crystal lattice (left), and a space-filing view of the $(M, M, M, P, P, P)$-2 enantiomer (right).

the most important structural features, we found abnormally large interplanar angles between the two terminal rings of a helicene: $49.0^{\circ}$ for the external [5] helicenes, and $69.9^{\circ}$ for the internal ones (mean values). The latter value is extreme, when compared to $[5]$ helicene $\left(46.0^{\circ}\right)^{13}$ and most carbohelicenes $\left(40-53^{\circ}\right) .^{3,13}$ These angles are indicative of an unusual helical stretch, with a larger helical pitch. It is more pronounced for the internal [5]helicenes than for the external ones. This is also in agreement with the calculated isomerization barriers in Figure 1: $130.0 \mathrm{~kJ} \mathrm{~mol}^{-1}$ for an external [5] helicene vs $151.8 \mathrm{~kJ} \mathrm{~mol}^{-1}$ for an internal one. In comparison with bond length in benzene $(1.393 \AA),{ }^{14}$ there is a marked alternation of "regular" $(1.401 \AA)$ and elongated $(1.437 \AA) \mathrm{C}-\mathrm{C}$ bonds in the central benzene core, a feature even accentuated in the central rings of the three 
external [5]helicenes (1.404 and $1.462 \AA$, respectively). The longest $\mathrm{C}-\mathrm{C}$ bonds in 2 are the six bonds radiating from the central benzene core with an average length of $1.462 \AA$. The central benzene core shows a chairlike conformation with a mean puckering angle of $14.1^{\circ}$ (angle between the mean plane defined by four coplanar atoms and the plane defined by one atom out of the previous plane and the two atoms directly attached to it). The central rings of the three external [5] helicenes exhibit a twist conformation with a torsion angle of $30.4^{\circ}$ (i.e., maximal dihedral angle in the ring). In summary, the triphenylene core in $\mathbf{2}$ is thus unusually twisted and distorted. Bond length alternation and elongation, deviation from planarity of benzene rings, and stretching of helicenes, are indicative of an overall deformation with some deficient local aromaticity, caused by an accumulation of helical strains. This is especially shown from the distortion of the central rings of external [5]helicenes, and from the central benzene core of 2 .

Having developed an efficient preparation of racemic $(M, M, M, P, P, P)-2$, we examined the configurational stability of the enantiomers. A chiral resolution of both enantiomers of 2 was analytically and semipreparatively achieved by HPLC on a chiral stationary phase using $(S, S)$-Whelk-01 columns. Enantiopure samples of both enantiomers were obtained on a multimilligram scale. As a result of its $3 \mathrm{D}$ propeller structure and unfavorable $\pi-\pi$ interactions in such distorted helicene units, enantiopure 2 was exceptionally soluble in chloroform (up to $33 \mathrm{~g} / \mathrm{L}$ ) as a large $\mathrm{PAH}$. The optical rotation of the first eluted enantiomer $(>99 \mathrm{ee})$ was measured at $[\alpha]_{\lambda}^{25}=-496\left(\mathrm{CH}_{2} \mathrm{Cl}_{2}, c=0.143\right)$ and the second eluted enantiomer $(98 \%$ ee $)$ afforded $[\alpha]_{\lambda}^{25}=+494$ $\left(\mathrm{CH}_{2} \mathrm{Cl}_{2}, c=0.143\right)$. The smaller optical rotation values of 2 , compared to those of helicenes (e.g., $-1670^{\circ}$ and $-3460^{\circ}$ for $(-)[5]$ helicene and $(-)[6]$ helicene, respectively), ${ }^{3 \mathrm{C}}$ are probably due to the presence of an equal number of $(P)$ - and $(M)$ configured [5] helicene units in 2. A good agreement between experimentally recorded VCD (vibrational circular dichroism) and ECD (electronic circular dichroism) spectra of the second eluted enantiomer of $\mathbf{2}$ and the simulated VCD and ECD spectra of the $(M, M, M, P, P, P)$ enantiomer of $\mathbf{2}$ allowed the assignment of absolute configurations (Figure 3 ). The first eluted enantiomer is most likely $(P, P, P, M, M, M)-2$, the second one being $(M, M, M, P, P, P)-2$. Because $(M)$-helicenes are usually levorotatory (and $(P)$-helicenes dextrorotatory), ${ }^{3 \mathrm{c}}$ this assignment is consistent with the negative $[\alpha]_{\lambda}^{25}$ value recorded for the first eluted $(P, P, P, M, M, M)-2$ due to the more pronounced helical chirality of internal $(M)$ - $[5]$ helicenes, than for the external $(P)$ ones. Also, the internal [5]helicenes are stereogenic units generating the molecular sense of the propeller helicity.

A photophysical study was undertaken with ( \pm )-2 (Figure 4). Three orange solutions in dichloromethane were prepared $(6.16$, $6.40,7.79 \mu \mathrm{M})$. The absorption spectra were recorded in triplicate $\left(\lambda_{\max }=392 \mathrm{~nm}\right.$; mean value of $\left.\varepsilon=59000 \mathrm{M}^{-1} \mathrm{~cm}^{-1}\right)$. The maximum wavelength absorption is similar to [5] helicene $\left(\lambda_{\max }=395 \mathrm{~nm}\right),{ }^{15}$ showing little influence of the extended $\pi$ system. A fluorescence emission spectra was measured $\left(\lambda_{\text {exc }}=\right.$ $\left.400 \mathrm{~nm} ; \lambda_{\max }=513 \mathrm{~nm}, \phi_{\mathrm{f}}=0.06\right)$. The absorption and emission spectra show little overlap, as it is often the case for $[n]$ helicenes, and a Stokes shift of $121 \mathrm{~nm}$ is found. The quantum yield was evaluated either from $\mathrm{Ru}(\mathrm{bpy})_{3}$ in water or Coumarin 343 in $\mathrm{EtOH}$. It is in the range of a nonfunctionalized $[n]$ helicene $(n>$ $\left.5 ; \phi_{\mathrm{f}} \approx 0.05\right) .{ }^{16}$ The fluorescence lifetime was recorded from the three solutions with the same results $(\tau=5.60 \mathrm{~ns})$.

In conclusion, a propeller-shaped chiral polyaromatic hydrocarbon molecule embedding six [5]helicene units was prepared
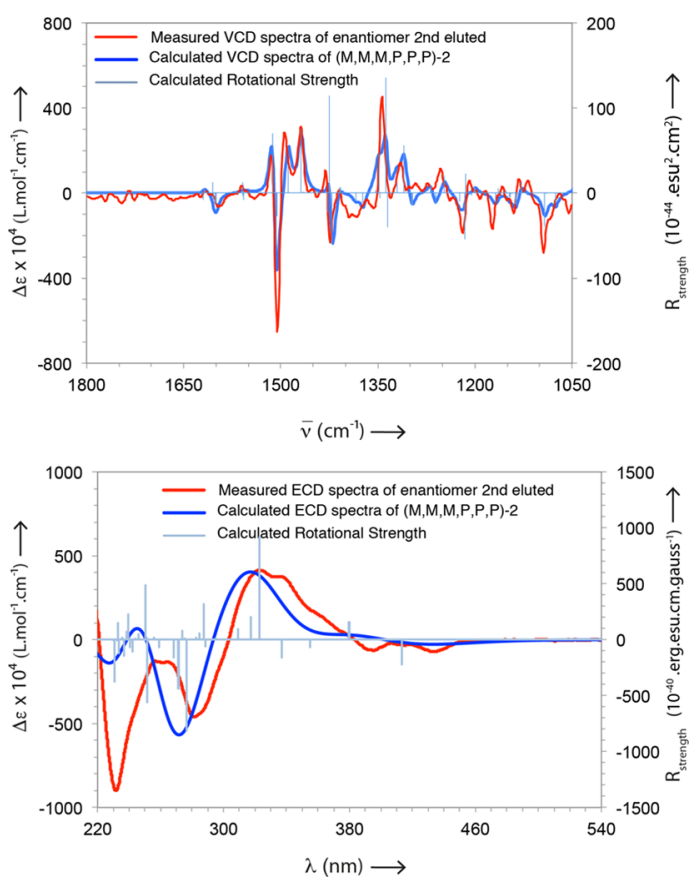

Figure 3. VCD (top) and ECD (bottom) spectroscopy studies comparing the experimental spectra of the second eluted enantiomer with the simulated spectra of the $(M, M, M, P, P, P)-2$ enantiomer (see SI for details).

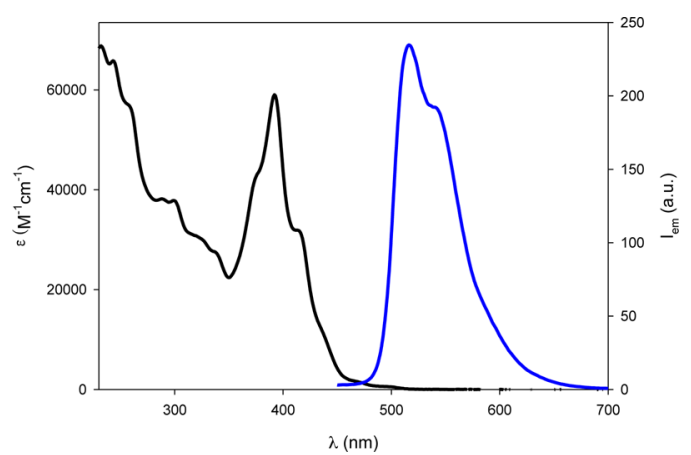

Figure 4. (a) Absorption spectra of $( \pm)-2$ in $\mathrm{CH}_{2} \mathrm{Cl}_{2}$ (black line: $\lambda_{\max }=$ $392 \mathrm{~nm} ; \varepsilon=59000 \mathrm{M}^{-1} \mathrm{~cm}^{-1}$ ); (b) emission spectra of 2 (blue line: $\lambda_{\text {exc }}$ $\left.=400 \mathrm{~nm} ; \lambda_{\max }=513 \mathrm{~nm} ; \phi_{\mathrm{f}}=0.06\right)$.

in one step from 7,8-dibromo[5]helicene by a nickel(0)promoted cyclotrimerization. The single-crystal X-ray diffraction analysis of this molecule revealed a severe distorted geometry of the triphenylene core, and a strong helical stretch of the three internal [5]helicenes leading to abnormally large interplanar angles between their two terminal rings. This is due to a considerable accumulation of dense helical strain. As a consequence, molecule 2 was configurationally stable, so that it was resolved and produced in enantiopure forms by chiral HPLC techniques. It allowed some chiroptical studies and assignment of the absolute configurations by VCD and ECD spectroscopies. A photophysical study of $( \pm)-2$ completed its characterization. This efficient synthetic approach to a configurationally stable propeller-shaped nanographenes opens up new avenues for their functionalization and higher analogs, ${ }^{17}$ and the development of this unique class of chiral materials with exalted properties, toward applications in materials science, chiroscience, and nanoscience. 


\section{ASSOCIATED CONTENT}

\section{S Supporting Information}

The Supporting Information is available free of charge on the ACS Publications website at DOI: 10.1021/jacs.7b07622.

Detailed experimental procedures, characterization of compounds, computational details, structural, spectroscopic, and enantiomerization data (PDF)

Crystallographic data for racemic 2 (CIF)

\section{AUTHOR INFORMATION}

\section{Corresponding Authors}

*yoann.coquerel@univ-amu.fr

*marc.gingras@univ-amu.fr

ORCID

Yoann Coquerel: 0000-0003-0646-006X

Marc Gingras: 0000-0003-3704-7024

Notes

The authors declare no competing financial interest.

\section{ACKNOWLEDGMENTS}

We thank Dr. Michel Giorgi (Aix-Marseille Université) for X-ray structural analysis, Pr. Stéphane Viel and Mrs. Roselyne Rosas (Aix-Marseille Université) for assistance with NMR spectrometry, Pr. Paola Ceroni (Univ. of Bologna) for photophysics, the Centre Régional de Compétences en Modélisation Moléculaire (Aix-Marseille Université) for computing facilities. Financial supports from Aix-Marseille Université, the Centre National de la Recherche Scientifique (CNRS), and CNRS PICS (No. PICS07573) with the University of Bologna are gratefully acknowledged. M.V. is thankful to the French-Italian University (Vinci Program) for a Ph.D. contract (No. C3-141).

\section{REFERENCES}

(1) Reviews: (a) Chen, L.; Hernandez, Y.; Feng, X.; Müllen, K. Angew. Chem., Int. Ed. 2012, 51, 7640-7654. (b) Celis, A.; Nair, M. N.; TalebIbrahimi, A.; Conrad, E. H.; Berger, C.; de Heer, W. A.; Tejeda, A. J. Phys. D: Appl. Phys. 2016, 49, 143001. (c) Ma, L.; Wang, J.; Ding, F. ChemPhysChem 2013, 14, 47-54.

(2) Books and Reviews: (a) Scarso, A.; Borsato, G. In Chirality at the Nanoscale, Nanoparticles, Surfaces, Materials and More; Amabilino, D., Ed.; Wiley-VCH: Weinheim, 2009; Chapter 2, pp 29-65. (b) Molecular Switches, $2^{\text {nd }}$ ed.; Feringa, B. L., Browne, W. R., Eds.; Wiley-VCH: Weinheim, 2011; Vol. 1. (c) Rieger, R; Müllen, K. J. Phys. Org. Chem. 2010, 23, 315-325.

(3) Recent reviews: (a) Rickhaus, M.; Mayor, M.; Juríček, M. Chem. Soc. Rev. 2016, 45, 1542-1556. (b) Gingras, M. Chem. Soc. Rev. 2013, 42, 968-1006. (c) Gingras, M.; Félix, G.; Peresutti, R. Chem. Soc. Rev. 2013, 42, 1007-1050. (d) Gingras, M. Chem. Soc. Rev. 2013, 42, 10511095. (e) Shen, Y.; Chen, C.-F. Chem. Rev. 2012, 112, 1463-1535.

(4) For some laterally $\pi$-extended helicenes: (a) Fujikawa, T.; Segawa, Y.; Itami, K. J. Org. Chem. 2017, 82, 7745-7749. (b) Bédard, A. C.; Vlassova, A.; Hernandez-Perez, A. C.; Bessette, A.; Hanan, G. S.; Heuft, M. A.; Collins, S. K. Chem. - Eur. J. 2013, 19, 16295-16302. (c) Buchta, M.; Rybacek, J.; Jancarik, J.; Kudale, K. K.; Budesinsky, M.; Chocholousova, J. V.; Vacek, J.; Bednarova, L.; Cisarova, I.; Bodwell, G. J.; Stary, I.; Stara, I. G. Chem. - Eur. J. 2015, 21, 8910-8917. (d) Bock, H.; Subervie, D.; Mathey, P.; Pradhan, A.; Sarkar, P.; Dechambenoit, P.; Hillard, E. A.; Durola, F. Org. Lett. 2014, 16, 1546-1549. (e) Chen, Y.; Marszalek, T.; Fritz, T.; Baumgarten, M.; Wagner, M.; Pisula, W.; Chen, L.; Müllen, K. Chem. Commun. 2017, 53, 8474-8477. (f) Ferreira, M.; Naulet, G.; Gallardo, H.; Dechambenoit, P.; Bock, H.; Durola, F. Angew. Chem., Int. Ed. 2017, 56, 3379-3382. For recent elongated helicenes: (g) Mori, K.; Murase, T.; Fujita, M. Angew. Chem., Int. Ed. 2015, 54, 6847-6851. (h) Sehnal, P.; Stara, I. G.; Saman, D.; Tichy, M.; Misek, J.;
Cvacka, J.; Rulisek, L.; Chocholousova, J.; Vacek, J.; Goryl, G.; Szymonski, M.; Cisarova, I.; Stary, I. Proc. Natl. Acad. Sci. U. S. A. 2009, 106, 13169-13174.

(5) For extended and configurationally stable helicenes: (a) Corannulene-helicene: Fujikawa, T.; Preda, D. V.; Segawa, Y.; Itami, K.; Scott, L. T. Org. Lett. 2016, 18, 3992-3995. (b) Quadruple helicenes: Fujikawa, T.; Segawa, Y.; Itami, K. J. Am. Chem. Soc. 2016, 138, 3587-3595. (c) Double [7] heterohelicene: Wang, X.-Y.; Wang, X.-C.; Narita, A.; Wagner, M.; Cao, X.-Y.; Feng, X.; Müllen, K. J. Am. Chem. Soc. 2016, 138, 12783-12786. (d) Benzo-fused double [7] carbohelicene: Hu, Y.; Wang, X.-Y.; Peng, P.-X.; Wang, X.-C.; Cao, X.Y.; Feng, X.; Müllen, K.; Narita, A. Angew. Chem., Int. Ed. 2017, 56, 3374-3378. (e) $\pi$-Extended double helicene: Fujikawa, T.; Segawa, Y.; Itami, K. J. Am. Chem. Soc. 2015, 137, 7763-7768. (f) Core-extended terrylene tetracarboxdiimide: Lütke Eversloh, C.; Liu, Z.; Müller, B.; Stangl, M.; Li, C.; Müllen, K. Org. Lett. 2011, 13, 5528-5531. (g) Perylene diimide helicenes: Schuster, N. J.; Paley, D. W.; Jockusch, S.; Ng, F.; Steigerwald, M. L.; Nuckolls, C. Angew. Chem., Int. Ed. 2016, 55, 13519-13523. (h) Triple [5] helicene: Saito, H.; Uchida, A.; Watanabe, S. J. Org. Chem. 2017, 82, 5663-5668. In the following studies, double [5] helicenes were possibly configurationally stable by modelisation (DFT calculations), but their separation into enantiomers was not reported: (i) Kashihara, H.; Asada, T.; Kamikawa, K. Chem. - Eur. J. 2015, 21, 6523-6527. (j) Luo, J.; Xu, X.; Mao, R.; Miao, Q. J. Am. Chem. Soc. 2012, 134, 13796-13803.

(6) Review: (a) Pérez, D.; Peña, D.; Guitián, E. Eur. J. Org. Chem. 2013, 2013, 5981-6013.

(7) Peña, D.; Escudero, S.; Pérez, D.; Guitián, E.; Castedo, L. Angew. Chem., Int. Ed. 1998, 37, 2659-2661.

(8) For hexabenzotriphenylene: (a) Peña, D.; Pérez, D.; Guitián, E.; Castedo, L. Org. Lett. 1999, 1, 1555-1557. For higher triphenylenes: (b) Wang, Y.; Stretton, A. D.; McConnell, M. C.; Wood, P. A.; Parsons, S.; Henry, J. B.; Mount, A. R.; Galow, T. H. J. Am. Chem. Soc. 2007, 129, 13193-13200. (c) Yanney, M.; Fronczek, F. R.; Henry, W. P.; Beard, D. J.; Sygula, A. Eur. J. Org. Chem. 2011, 2011, 6636-6639. (d) Lin, J. B.; Shah, T. K.; Goetz, A. E.; Garg, N. K.; Houk, K. N. J. Am. Chem. Soc. 2017, 139, 10447-10455. For alternative synthetic approaches: (e) Pradhan, A.; Dechambenoit, P.; Bock, H.; Durola, F. Angew. Chem., Int. Ed. 2011, 50, 12582-12585. (f) Pradhan, A.; Dechambenoit, P.; Bock, H.; Durola, F. J. Org. Chem. 2013, 78, 2266-2274. See also reference 5 h.

(9) (a) Rüdiger, E.; Rominger, F.; Steuer, L.; Bunz, U. H. F. J. Org. Chem. 2016, 81, 193-196. (b) Rüdiger, E. C.; Porz, M.; Schaffroth, M.; Rominger, F.; Bunz, U. H. F. Chem. - Eur. J. 2014, 20, 12725-12728. (c) Zhou, Z.-h.; Yamamoto, T. J. Organomet. Chem. 1991, 414, 119127.

(10) From the experimental barrier, $t_{1 / 2}=100000$ years at $25{ }^{\circ} \mathrm{C}$ (considering the barrier independent of temperature).

(11) Goretta, S.; Tasciotti, C.; Mathieu, S.; Smet, M.; Maes, W.; Chabre, Y. M.; Dehaen, W.; Giasson, R.; Raimundo, J.-M.; Henry, C. R.; Barth, C.; Gingras, M. Org. Lett. 2009, 11, 3846-3849.

(12) Idelson, A.; Sterzenbach, C.; Jester, S.-S.; Tschierske, C.; Baumeister, U.; Höger, S. J. Am. Chem. Soc. 2017, 139, 4429-4434.

(13) (a) Kuroda, R. J. Chem. Soc., Perkin Trans. 2 1982, 7, 789-794. (b) Chen, C.-F.; Shen, C.-Y. In Helicene Chemistry, From Synthesis to Applications; Springer: Berlin, 2017; pp 21-22.

(14) Allen, F. H.; Kennard, O.; Watson, D. G.; Brammer, L.; Orpen, A. G.; Taylor, R. J. Chem. Soc., Perkin Trans. 2 1987, 0, S1-S19.

(15) Clar, E.; Stewart, D. G. J. Am. Chem. Soc. 1952, 74, 6235-6238.

(16) Birks, J. B.; Birch, D. J. S.; Cordemans, E.; Vander Donckt, E. Chem. Phys. Lett. 1976, 43, 33-36.

(17) We obtained some experimental evidence in the formation of higher analogs of $\mathbf{2}$ and we are currently working in that direction. 